\title{
ANAESTHESIA FOR CERVICAL OSTEOTOMY
}

\author{
Jone Chang, M.D., F.R.C.P.(c)*
}

Cervical OSTEOTOMY for severe ankylosing spondylitis involving the cervical spine is uncommon. Yet, there are occasions when one may be called upon to provide anaesthesia for such an operation. At present there are no comprehensive reports on its anaesthetic management.

The largest series of cervical osteotomy was reported by Simmons of Toronto, who at the time of his report had operated on 20 such cases. ${ }^{1}$ Because of the diffculties and complications associated with tracheal intubation, all cases had been done under local anaesthesia with supplementary neuroleptic agents or with nitrous oxide inhalation during the osteotomy itself., ${ }^{1,2,3}$

Ankylosing spondylitis often is complicated by very severe fixed flexion deformity of the cervical spine, total ankylosis of all vertebrae, and complete fixation of the chest cage. Because of the fixed flexion deformity of the cervical spine, tracheal intubation is the most difficult part in the anaesthestic management. Ankylosis of the entire spine is usually accompanied by fusion of the ribs to the vertebrae, which restricts the expansion of the chest cage. This results in a marked decrease in vital capacity and other respiratory volumes which may lead to respiratory insufficiency during and after anaesthesia.

This presentation reports on the anaesthetic management for cervical osteotomy of two patients with severe fixed flexion deformity of the cervical spine.

\section{Anaesthetic Considerations and Technique}

The most important consideration in the management of these patients is to plan the approach to tracheal intubation. At no time must the patient's safety be compromised. If intubation is impossible, the operation should be carried out under local anaesthesia so that the airway may remain patent at all times. It follows that the patient must be fully awake during the period of attempted intubation. Consequently, the patient is given a belladonna drug only for pre-operative medication without any additional sedative or depressing agents.

On arrival in the operating room, blood pressure, heart rate and respiration are checked. A transtracheal block is performed with $2 \mathrm{ml}$ of 4 per cent lidocaine (Xylocaine ${ }^{\circledR}$ ) and the nasal passages and pharyngeal mucosa are anaesthetized by means of a topical lidocaine spray. The trachea is then intubated through the nose using a 6.0 or $6.5 \mathrm{~mm}$ naso-tracheal tube. It is important that a smaller tube than usual be used because too large a tube may cause discomfort and epistaxis. Once the tube has been passed into the oropharynx, two fingers are inserted

"Department of Anaesthesia, Vancouver General Hospital, Faculty of Medicine, University of British Columbia. 


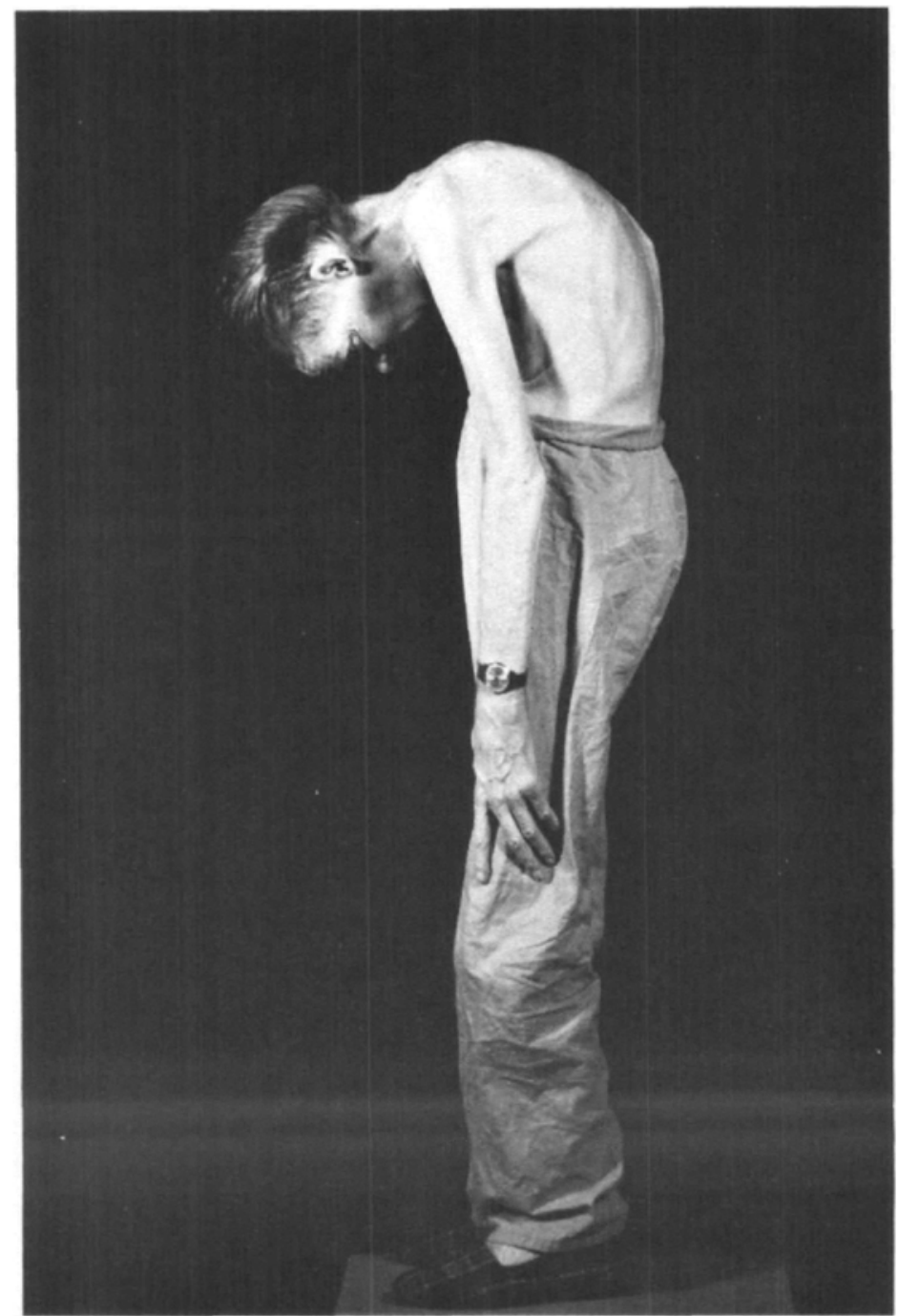

Frgure 1. Case 1. Patient before operation.

through the mouth to guide the tracheal tube through the laryngeal opening. If the mucosa has been well anaesthetized, neither this manoeuvre nor the introduction of the tube into the trachea cause any significant discomfort. Once the tube is in position, small doses of thiopentone are given to induce anaesthesia. Anaesthesia is maintained with nitrous oxide supplemented by an intravenous drip of alphaprodine (Nisentil(B). Respiration is spontaneous or assisted when required. Spontaneous respiration is the best guide to the amount of alphaprodine required for supplementation. With this technique, the patient is awake at the end of the operation. 


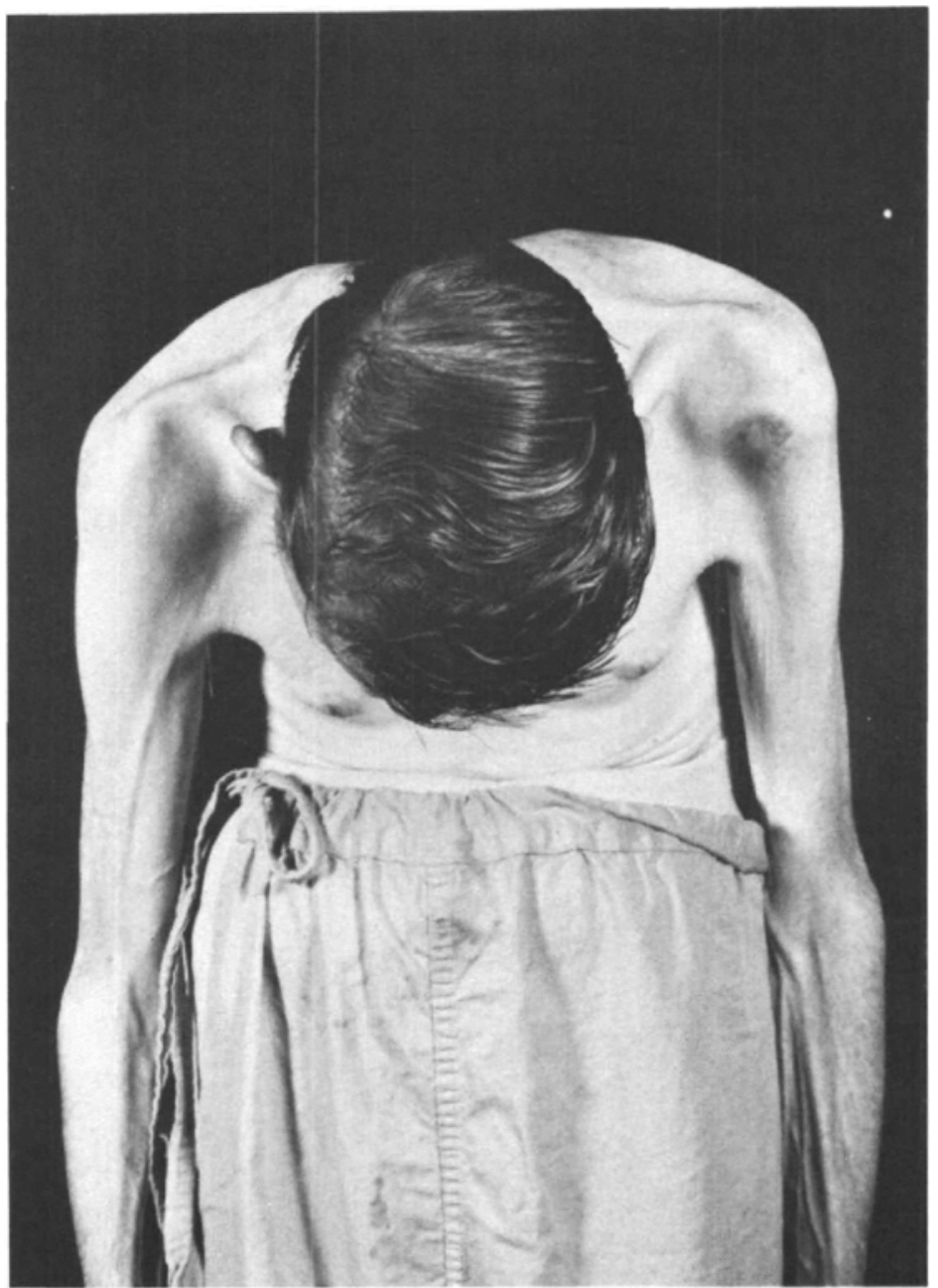

Figure 2, Case 1. Anterior view.

\section{Case Reports}

\section{Case \#1}

Male, age 39

V.C. 1660 cc $50 \%$

$\mathrm{Hb} 9.6 \mathrm{gm}$ to $13.9 \mathrm{gm}$

M.B.C. $84 \%$

The patient was very emaciated with a history of anaemia and nephropathy complicating the ankylosing spondylitis. Premedication was with hyoscine 0.5 mg intramuscularly 90 minutes pre-operatively.

Intubation, induction, and maintenance was as described above, using a 6.0 $\mathrm{mm}$ cuffed nasotracheal tube, thiopentone $275 \mathrm{mg}$, nitrous oxide and alphaprodine $168 \mathrm{mgm}$, with spontaneous respiration. A prophylactic tracheostomy was per- 


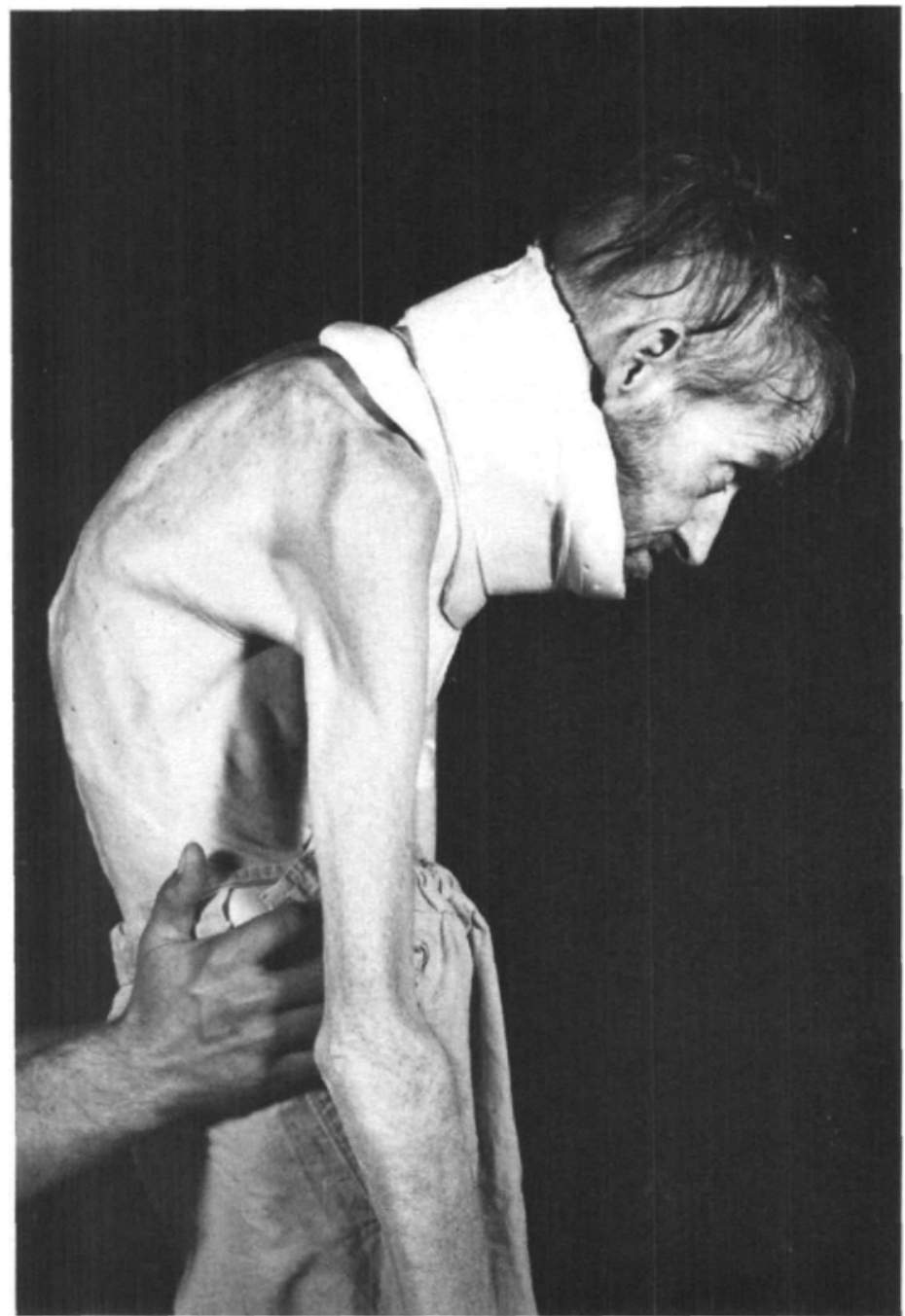

Figure 3. Case 1. Patient after operation.

formed at the completion of the operation because the patient was stabilized on Crutchfield tongs and any manipulation associated with airway management might dislocate the osteotomy. The immediate post-operative course was uneventful and the tracheostomy was removed 24 hours after operation. Two weeks later, the patient developed cough and sputum accompanied by fever, tachycardia, and signs of respiratory failure. This pneumonic process was treated vigorously with antibiotics and the patient recovered rapidly. He was discharged from hospital five weeks after operation.

\section{Case \#2}

Male, age 57

V.C. $1667 \mathrm{cc} 51 \%$

$\mathrm{Hb} 13.9 \mathrm{gm}$

M.B.C. $76 \%$ of normal

E.C.G.: Frequent ventricular premature beats and bigeminal rhythm. 


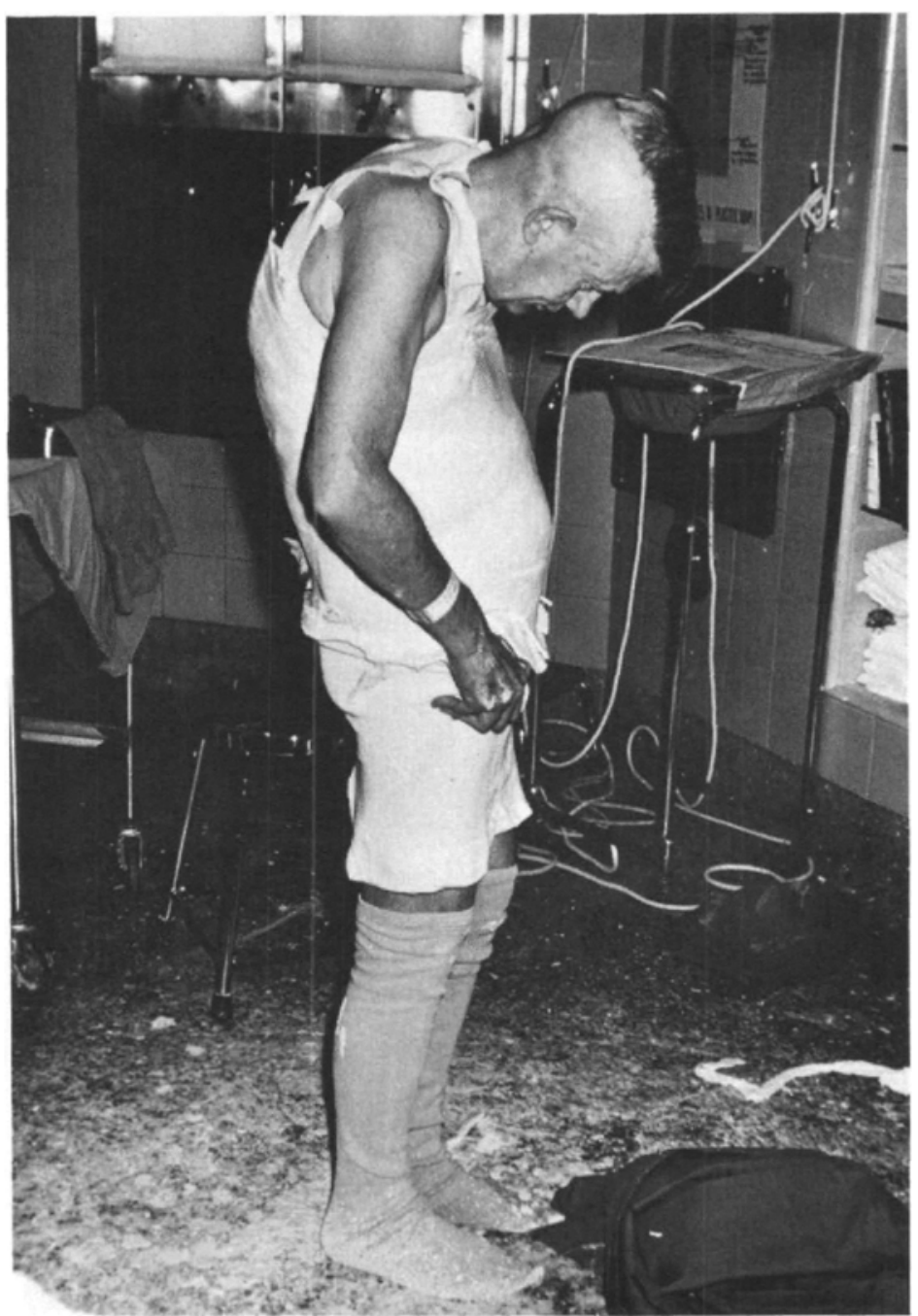

Figure 4. Case 2. Patient fitted with body spica before operation.

One of his complaints was difficulty in opening his mouth because the jaw was against the chest. Pre-operatively the patient had been placed into a halo apparatus and plaster body spica.

Premedication was hyoscine $0.6 \mathrm{mg}$ intramuscularly one hour before operation. Intubation, induction and maintenance of anaesthesia were identical to the previous case, except that only $50 \mathrm{mgm}$ of alphaprodine were required. Nalorphine (Nalline ${ }^{\circledR}$ ) $2.5 \mathrm{mg}$ was given intravenously at the conclusion of the anaesthetic, at which time the patient was awake. The trachea was extubated in the recovery room. The osteotomy was stabilized with a body spica and the halo apparatus so that nursing care was easier and any potential manipulations of the airway would not have disturbed the osteotomy.

The patient had an uneventful course post-operatively. 


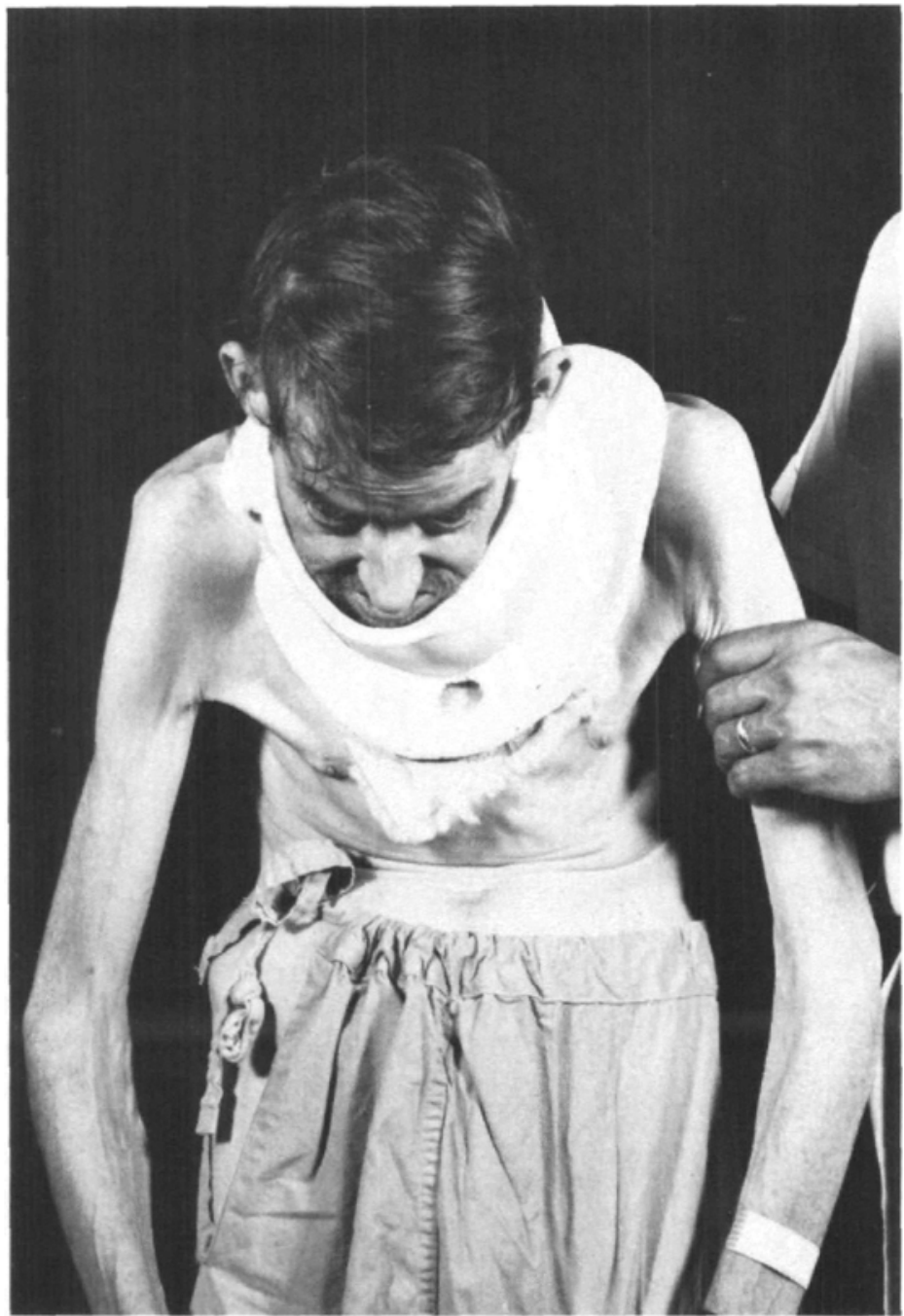

Figure 5. Case 2. Anterior view.

\section{Discussion}

These two cases of ankylosing spondylitis with fixed severe cervical deformities demonstrate that general anaesthesia can be administered safely. It is apparent that the patient's airway may be compromised if the respiratory mechanics are disturbed prior to the establishment of tracheal anaesthesia, because of the technical difficulties involved in intubation. It is imperative that intubation be carried out with the patient awake and that the mechanics of respiration remain undisturbed. If this is done and if the intubation should prove to be impossible, the patient's safety will not be compromised and no tragedy will occur. Once tracheal intubation has been accomplished, the maintenance of anaesthesia becomes routine. 


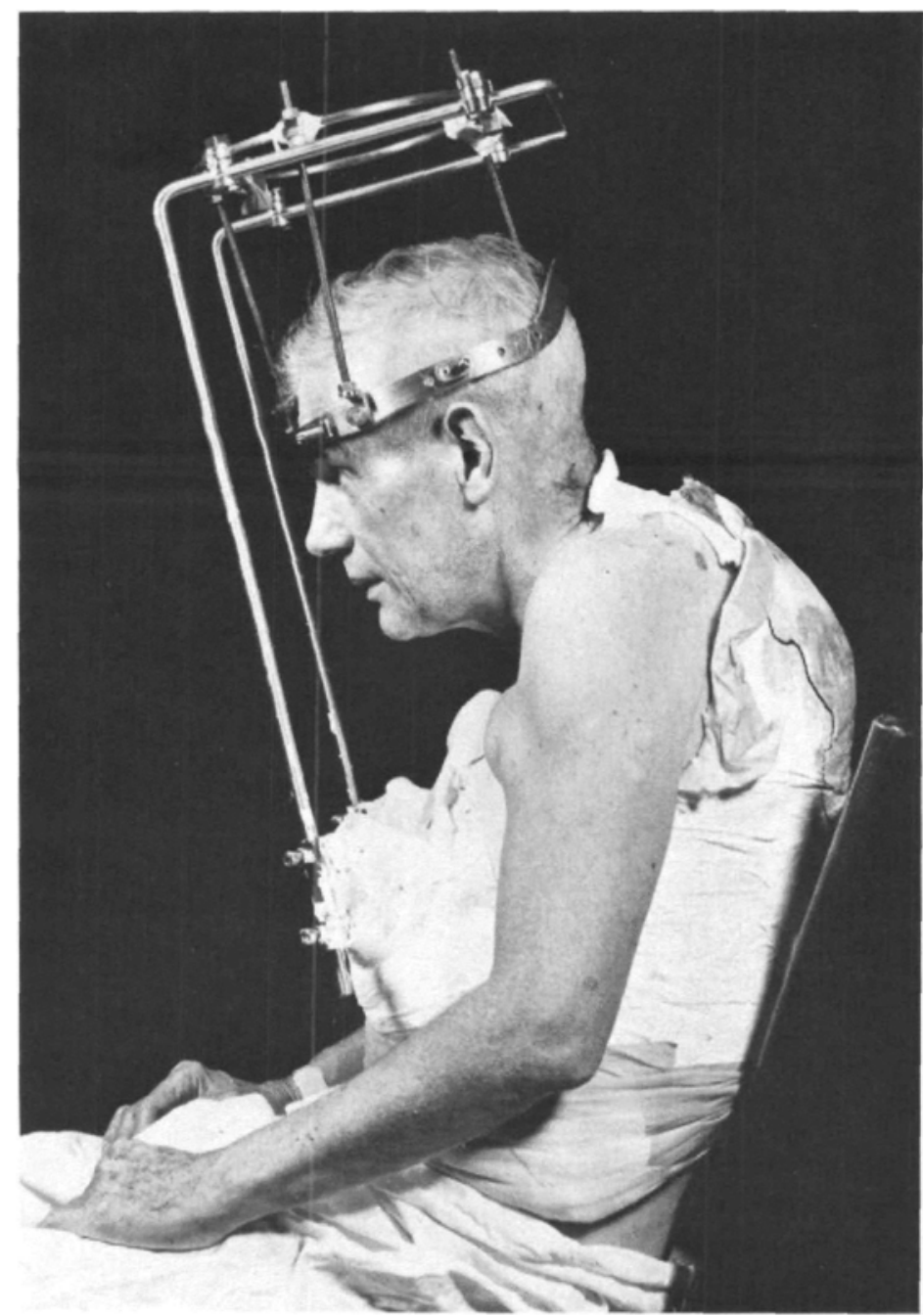

Figure 6. Case 2. Patient after operation.

Cardiac arrest has been reported during an operation under local anaesthesia. ${ }^{4}$ The situation was complicated by a body spica which impeded resuscitation. It may be necessary to have the body spica bivalved prior to the operation so that there will be no delay in resuscitation if cardiac arrest should occur. Pneumothorax has occurred from puncture of the pleura during the operation. ${ }^{3}$

Lastly, one must be concerned about pulmonary function in the post-operative period because of the decrease in chest expansion. These patients should have vigorous chest physiotherapy to prevent pulmonary complications.

\section{SUMMARY}

The problem related to the management of anaesthesia for cervical osteotomy in ankylosing spondylitis with severe fixed flexion deformities have been reviewed. 


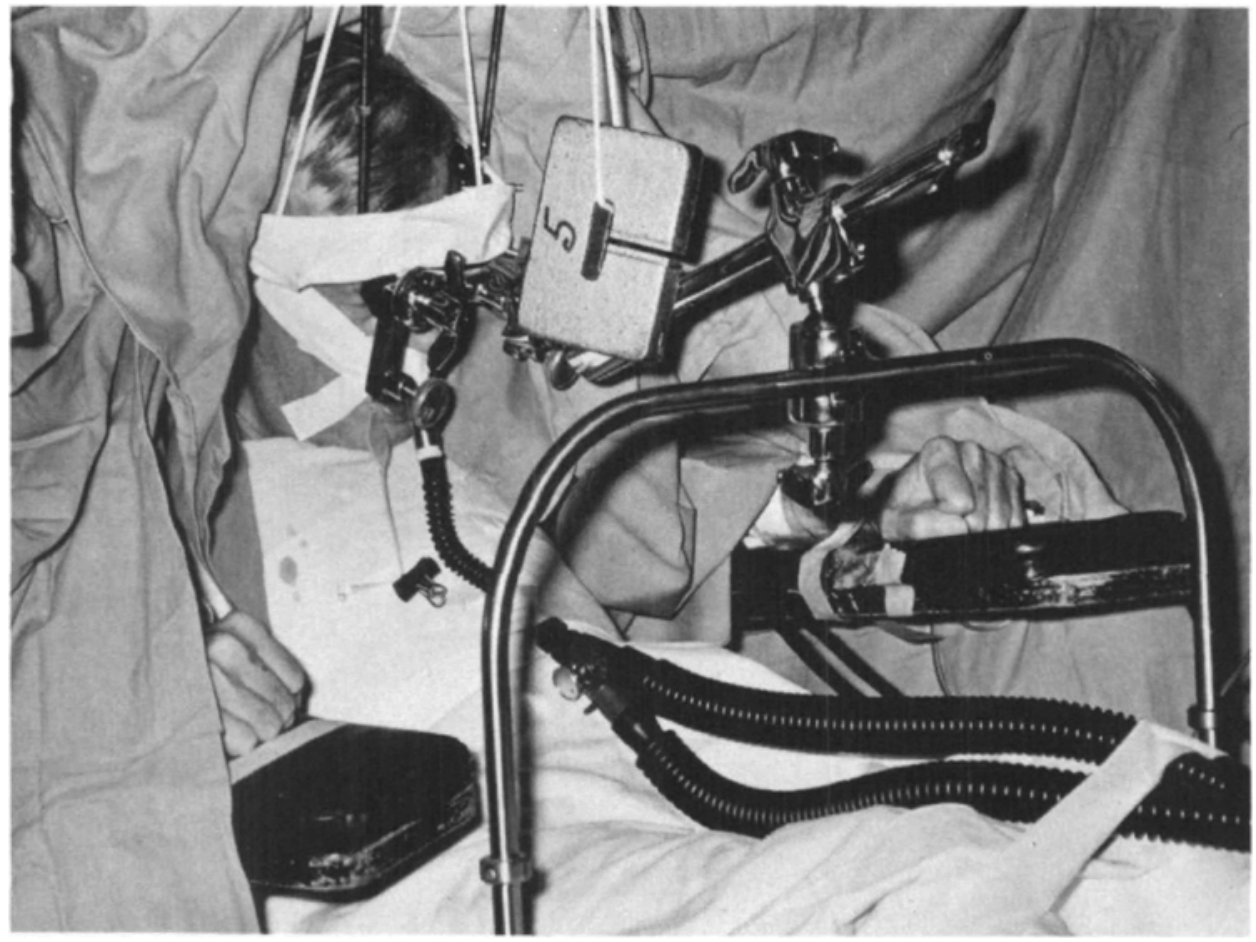

Figure 7. Case 2. Patient is positioned on an operation room table with the halo apparatus resting on a Craig head rest.

The two cases presented indicate that general anaesthesia can be provided safely without undue difficulty. The most important consideration in the management is to conduct the anaesthesia without compromising airway patency and ventilation.

\section{REsuMÉ}

Nous avons fait une revue des problèmes que pose la conduite de l'anesthésie pour ostéotomie cervicale dans la spondylite ankylosante avec déformations en flexion fixe prononcée. Les deux cas que nous avons présentés démontrent que l'anesthésie générale peut être employée en toute sécurité sans difficultés majeures. Le point le plus important dans la conduite de l'anesthésie est de maintenir libres les voies respiratoires et d'assurer une ventilation adéquate.

\section{ACKNOWLEDGMENTS}

I wish to thank Dr. F.P. Patterson and his staff for their assistance and for supplying the photographs for this publication. 


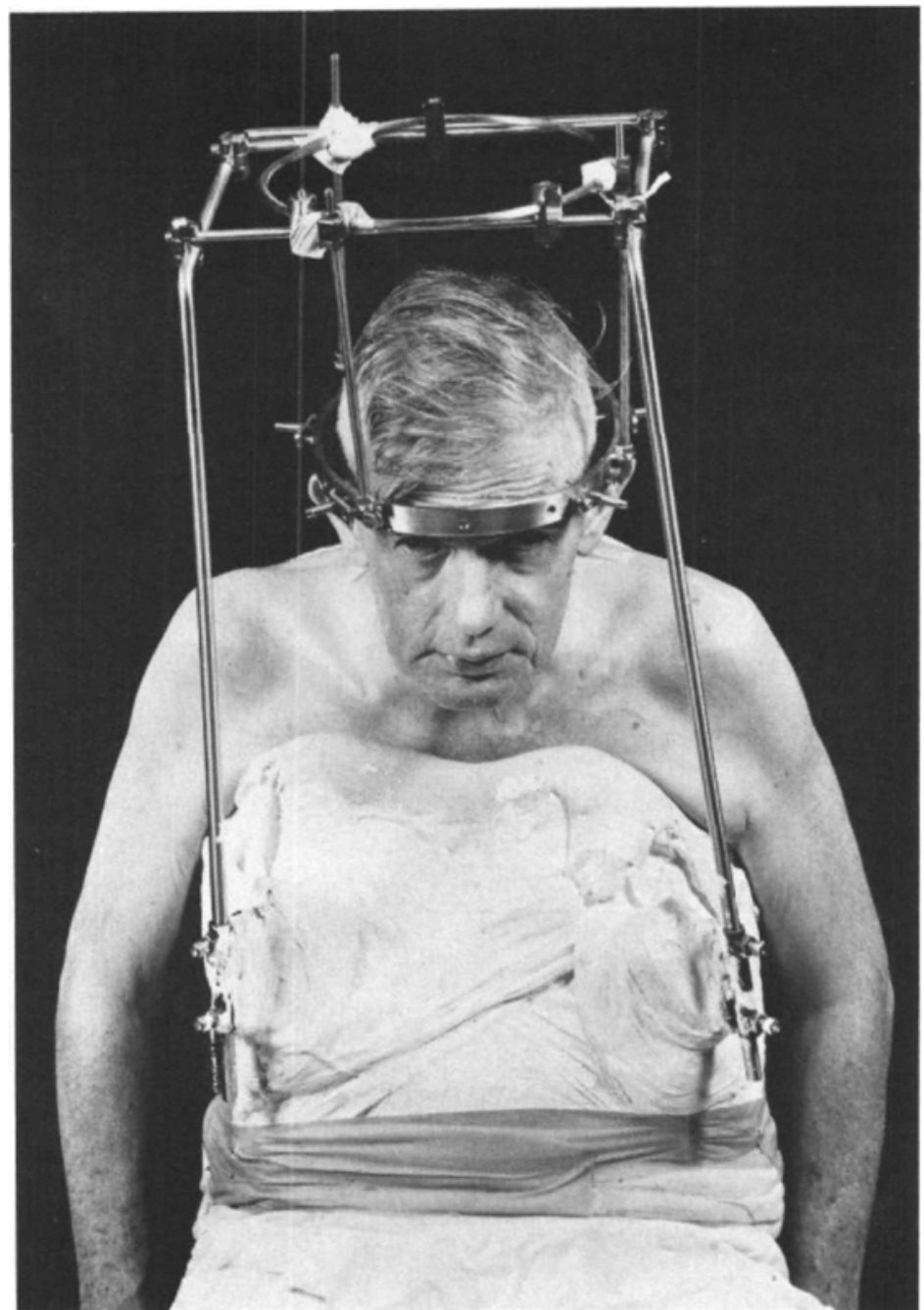

Figure 8. Case 2 after surgery. The patient is stabilized on the halo apparatus.

\section{REFERENCES}

1. Simmons, E.H. The surgical correction of flexion deformity of the cervical spine in ankylosing spondylitis. Clinical Orthopaedics and Related Research 86: 132 (1972).

2. URIST, M.R. Osteotomy of the cervical spine, report of case of ankylosing rheumatoid spondylitis. J. Bone Joint Surg. 40A: 833 (1958).

3. Mason, D., Dozen, L., \& Adezstein, L. Surgical correction of flexion deformity of the cervical spine. California Med, 79: 244 (1953).

4. Srmmons, E.H. Personal communications. 